\section{Carson no 'beacon of reason' on DDT}

We disagree with Rob Dunn's view that Rachel Carson's 1962 book on human environmental impacts, Silent Spring, still stands as a "beacon of reason" (Nature 485, 578-579; 2012).

The insecticide DDT (dichlorodiphenyltrichloroethane) was arguably the most successful chemical ever synthesized to control malaria and other insect-borne diseases. However, Silent Springled to a US ban on DDT use in 1972.

Carson branded DDT as dangerous because of its effects at high doses on experimental rodents and birds. But it was already known that humans experienced no ill effects after consuming 35 milligrams of DDT daily for two years - a dose 1,000 times higher than that received from agricultural exposure. Thousands of pesticides occur naturally in fruit and vegetables and are consumed daily. Around half of these also cause cancer at high doses in rodent tests (B. N. Ames and L.S. Gold Mutat. Res. 447, 3-13; 2000).

DDT is an organohalogen and is concentrated in the food chain, as are many of the organohalogens naturally synthesized by marine and land organisms; some are also found in breast milk (G. W. Gribble Chemosphere 52, 289-297; 2003). But persistence does not equate to harm.

Carson claimed that insect resistance would quickly reduce DDT's effectiveness. But DDT is largely a mosquito repellent, not a toxicant. Repellent resistance has not yet emerged, whereas toxicant resistance is widespread.

Contrary to Dunn's claims and Carson's predictions, the bald eagle had become rare long before DDT, and American robins increased during the 1960s.

At the time of the DDT ban in 1972, 1 billion people were almost malaria-free. Within a few years, malaria cases had risen 10-100-fold. Over 40 years, estimates suggest that there have been 60 million to 80 million premature and unnecessary deaths, mainly children, as a result of misguided fears based on poorly understood evidence. Tony Trewavas ${ }^{\star}$ University of Edinburgh,UK.trewavas@ed.ac.uk ${ }^{*}$ On behalf of 11 co-signatories (see go.nature.com/2hfmok).

\section{Help to survey the use of smart drugs}

We call on Nature readers to help us to achieve the highest possible response from students in the United Kingdom or Ireland to a survey on the use of pharmacological drugs for cognitive enhancement (see www.thesmartdrugstudy.com).

In 2007, Nature urged academic institutions to address the ethical and regulatory challenges associated with the use of psychotropic drugs that improve cognitive performance in the healthy - notably medications for attention-deficit hyperactive disorder (ADHD) and narcolepsy (Nature 450, 320; 2007). The following year, an informal global survey by Nature suggested that as many as one in five academics used cognition-enhancing drugs for non-medical reasons (Nature 452, 674-675; 2008).

Outside the United States and Germany, empirical evidence on the use of cognitive enhancers is sparse (for a review, see C. I. Ragan, I. Bard \& I. Singh Neuropharmacology; in the press). UK policy discussions have relied mainly on ambiguous US data.

Our survey, in collaboration with the UK Independent Scientific Committee on Drugs, will provide a comprehensive analysis of the use of pharmacological cognitive enhancers by students in the broader context of their substance use. We shall use the results to assess prevalence, concerns, frequency and motivation, and sources and pricing. We will also analyse the perceived effects and side effects, perceptions of social coercion and regulatory measures, and correlation with self-reported ADHD symptoms. Imre Bard, Ilina Singh London School of Economics \& Political Science, London, UK. i.a.singh@lse.ac.uk

\section{Less lactation may explain cancer rise}

Your Outlook supplement on breast cancer (Nature 485, S49S66; 2012) does not mention the protective effect of breastfeeding. In most populations, this seems to be even stronger than that conferred by regular exercise (Nature 485, S62-S63; 2012), especially when lactation is extended over several children (S. Ip et al. Evid. Rep. Technol. Assess. 153, 1-186; 2007).

Genetic factors and early puberty both play a part in development of the disease. But these cannot fully account for the increasing incidence of breast cancer in the developed world, given that the genetic make-up of populations is unlikely to have changed much over the past few decades and puberty now starts only slightly earlier.

One change is that Western families have become smaller, so total breastfeeding over a mother's lifetime has declined. Oestrogen exposure, normally suppressed during lactation, is therefore effectively prolonged, increasing the likelihood of developing some types of breast tumour.

Anne Marie Oudesluys-Murphy Leiden University Medical Centre, Leiden, the Netherlands. h.m.oudesluys-murphy@lumc.nl

\section{Limit consumption to preserve habitats}

Consumption by wealthy nations is driving environmentally hostile production in the developing world, which can threaten species and their habitats (see, for example, M. Lenzen et al. Nature 486, 109-112; 2012). But balancing this unsustainable ecological debt won't be straightforward.

Although consumptioncurbing policies in wealthy nations are urgently needed, their potential for adverse effects on the development of poor countries must be taken into account. Changes in demand through international trade could compromise many livelihoods, holding back sustainable development.

Governments in the developing world can help by strengthening their regulations to eliminate environmentally damaging production techniques, with technical and financial assistance from rich nations if necessary.

In summary, possible solutions should consider the interests and needs of both developed and developing nations (see, for example, the latest United Nations report on economic development in Africa; go.nature.com/qjmusf). Marco Sakai Sustainability Research Institute, University of Leeds,UK.ee08masd@leeds.ac.uk

\section{Clue to an ancient cosmic-ray event?}

It is tempting to speculate that the ancient text of the Anglo-Saxon Chronicle might offer a clue to the cause of the mysterious, dramatic cosmic-ray event in AD 774 (F. Miyake et al. Nature 486, 240-242; 2012).

A chronicle entry for the same year (see go.nature.com/ wwkw5j) hints at the presence of a supernova largely hidden behind a dust cloud, which would scatter and absorb all light bar a trickle of red. The resulting supernova remnant would be invisible.

The entry notes: “This year also appeared in the heavens a red crucifix, after sunset; the Mercians and the men of Kent fought at Otford; and wonderful serpents were seen in the land of the South-Saxons."

Jonathon Allen University of California, Santa Cruz, California, USA.jokallen@ucsc.edu 